\title{
Pier Vellinga, 2013, Le changement climatique, mythes, réalités et incertitude, Bruxelles, Éditions de l'Université de Bruxelles, 152 pages.
}

\section{Caroline Norrant-Romand}

\section{(2) OpenEdition}

1 Journals

Édition électronique

URL : http://journals.openedition.org/developpementdurable/10191

DOI : 10.4000/developpementdurable.10191

ISSN : 1772-9971

Éditeur

Association DD\&T

\section{Référence électronique}

Caroline Norrant-Romand, «Pier Vellinga, 2013, Le changement climatique, mythes, réalités et incertitude, Bruxelles, Éditions de l'Université de Bruxelles, 152 pages. », Développement durable et territoires [En ligne], Vol. 5, $n^{\circ} 1$ | Février 2014, mis en ligne le 04 février 2014, consulté le 22 septembre 2020. URL http://journals.openedition.org/developpementdurable/10191 ; DOI : https://doi.org/10.4000/ developpementdurable.10191

Ce document a été généré automatiquement le 22 septembre 2020

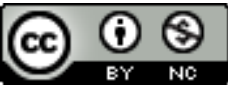

Développement Durable et Territoires est mis à disposition selon les termes de la licence Creative Commons Attribution - Pas d'Utilisation Commerciale 4.0 International. 
Pier Vellinga, 2013, Le changement

climatique, mythes, réalités et incertitude, Bruxelles, Éditions de l'Université de Bruxelles, 152 pages.

Caroline Norrant-Romand

Uisire

Enjeus

Pier Vellinga

Le changement climatique, mythes, réalités et incertitudes

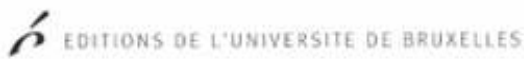

Cet ouvrage se propose de faire un point sur le changement climatique et les différentes idées qui circulent à son sujet. L'auteur, Pier Vellinga, Professeur à la Vrije Universiteit d'Amsterdam et à l'université de Wageningen, est un expert de ce 
domaine. Il donne donc à travers cet ouvrage les principaux concepts nécessaires à la compréhension du système climatique et du changement qui l'affecte, et examine les diverses "vérités" énoncées à son sujet, le tout sur un ton très pédagogique et donc accessible à un très grand public.

2 En effet, après une préface de présentation écrite par Ph. Bourdeau, F. Pattyn et E. Zaccaï, l'ouvrage se décline en neuf chapitres répondant chacun à une question d'ordre général que quiconque s'intéressant un jour au changement climatique avec un esprit quelque peu critique pourrait se poser. Ainsi, le premier chapitre, intitulé: "le changement climatique : qui croire ?" revient sur l'origine et l'influence des surplus de gaz à effet de serre et explique le fonctionnement du système climatique, de même que divers éléments qui entrent en jeu dans la variabilité du climat tels que le soleil, les volcans ou encore les phénomènes El Niño. Ce chapitre précise aussi l'influence de l'homme, les différentes solutions envisageables pour limiter le changement climatique, et fait le point sur la collaboration internationale sur cette question.

3 Le chapitre deux, quant à lui, s'interroge sur une éventuelle exagération du discours par les climatologues. Pour répondre à cette question, l'auteur revient sur les modèles et scénarios climatiques, sur les propos alarmistes du Club de Rome, et détaille également les processus des pluies acides, de la diminution de concentration de la couche d'ozone, mais également la communication entre science et politique.

4 Le troisième chapitre s'interroge sur la réalité d'un réchauffement alors que certaines régions subissent les hivers les plus froids « jamais connus ». Pour cela, l'auteur détaille différents points : est-il vrai que le climat se réchauffe ? Il analyse également le rôle du soleil et explique comment les scientifiques sont sûrs que le réchauffement moyen constaté est imputable aux gaz à effet de serre et non au soleil. Il termine ce chapitre par les prévisions du GIEC de 1990 pour la température en 2100.

5 Dans le quatrième chapitre, c'est l'influence humaine sur le réchauffement qui est interrogée, et notamment pour savoir si cette influence ne serait pas surestimée. Pour ce faire, l'auteur revient sur les périodes glaciaires, les gaz à effet de serre et le réchauffement, le cycle du carbone, les volcans, et s'interroge pour savoir si une période glaciaire à venir pourrait compenser le réchauffement.

6 Le chapitre cinq s'interroge sur la gravité d'un monde un peu plus chaud. Pour cela, l'auteur examine diverses possibilités, parmi lesquelles un réchauffement de un ou deux degrés, puis de trois, quatre degrés ou plus. Il explique ce que sont les points de basculement, et s'interroge sur la stabilité du système climatique. Ensuite, il revient sur le gaz carbonique et l'acidification des océans, tout en s'interrogeant si le $\mathrm{CO}_{2}$ est un poison. Enfin, il aborde la question des catastrophes naturelles en lien avec le changement climatique, mais aussi les assureurs et les dommages que ces catastrophes peuvent causer, ainsi que les responsabilités en cas de dommages dus au climat.

7 Le chapitre six pose la question de «simplement» s'adapter au changement climatique : par la diminution des émissions ou l'adaptation, et ainsi le problème économique qui risque d'en découler. L'auteur définit ce qu'est l'adaptation, et détaille les diverses solutions envisagées pour els Pays-Bas et dans l'Union européenne.

8 Le chapitre sept envisage le recours à d'autres sources d'énergie, notamment sur son aspect financier. L'auteur s'étend alors sur les problèmes afférents au stockage souterrain $\mathrm{du} \mathrm{CO}_{2}$ et à l'énergie nucléaire, sur l'énergie durable et l'augmentation de l'efficacité énergétique, sur la mobilité et les transports et sur le fait de manger moins 
de viande. Enfin, bien que le $\mathrm{CO}_{2}$ monopolise le discours, il s'interroge également sur les autres gaz à effet de serre.

9 Dans le chapitre huit, l'auteur revient sur les mythes, les réalités et les incertitudes liés au changement climatique : pour ce faire, il commence par faire le point sur les réalités, puis expose et démonte les différents mythes qui circulent. Ensuite, il expose les véritables incertitudes qui subsistent sur la question du changement climatique.

10 Enfin, dans le chapitre neuf, l'auteur expose les perspectives : pourquoi les États-Unis hésitent-ils à limiter les émissions ? Que réserve l'avenir ? Puis il termine ce chapitre en présentant la position de l'Europe.

11 Cet ouvrage, très bien écrit (quoique souffrant quelques rares fois d'inexactitudes de traduction), a le mérite de faire le point sur cette question très présente du changement climatique, en revenant sur les faits scientifiques mais également en examinant toutes les hypothèses et contrevérités qui circulent au sujet de cette question parfois très controversée. Son grand avantage est qu'il s'adresse à un public très vaste, non spécialiste, en des termes simples et accessibles à tous, sans pour autant tomber dans une simplification outrancière qui le réduirait à l'état de caricature. Cela reste donc un ouvrage très sérieux et très accessible, indispensable pour bien comprendre le changement climatique actuel et tous ses enjeux.

\section{AUTEUR}

\section{CAROLINE NORRANT-ROMAND}

Caroline Norrant-Romand est Maître de Conférences en Géographie, spécialisée en Climatologie, à l'Université Lille 1 - Nord de France, C. Norrant-Romand travaille sur le thème du changement climatique, particulièrement en région méditerranéenne et sur l'Europe. 